\title{
Building a quality home for fluorescence
}

Dear Authors, Reviewers and Editors

With the announcement of our first impact factor of 2.429, and the recent news that the journal will be indexed by MEDLINE and searchable from the PubMed ${ }^{\circledR}$ database, this year has been a very exciting year for the journal. After only a few years, the journal is already establishing itself as the home of the highest quality fluorescence research. Our desire has been for a journal in our area which could showcase the best work in fluorescence and so give a fitting home for what is a truly multi-disciplinary field, combining cutting edge optical and imaging techniques with organic and biochemistry to address major issues in biology and medicine.

This desire has borne fruit in the latest volume, where we can read reviews on super-resolution of the neuron', cyan fluorescent proteins ${ }^{\mathrm{ii}}$, lanthanide-doped fluorescent oxides and salts ${ }^{\mathrm{iii}}$, fluorescent polarization assays in drug discovery ${ }^{\text {iv }}$ and site-specific structural dynamics of $\alpha$ Synuclein revealed by time resolved fluorescence spectroscopy ${ }^{v}$.

We express our thanks to those who have entrusted us to publish their research in the journal. These days there are more and more journals we could choose from, however being a community led and run initiative, supported by a learned society publisher, we strive to offer authors a more personal service than many other journals. If you have not yet published in Methods and Applications in Fluorescence, we encourage you to send your next research paper to us; most authors receive a decision on their article in 6-7 weeks and articles are available online as soon as they are accepted, giving fast visibility for your best work. As a new online journal we also offer you the chance to get your message across in a more informal way, through a video abstract, which can also be used to show some of the faces behind the names as in the informative video prepared by Silvia Giordani and her team ${ }^{\mathrm{vi}}$.

Looking forward to the coming year, we are planning a special issue on Fluorescence research in South America as well as one on Fluorescence research in China, two regions of the world where high quality research is being done but hasn't always received the exposure it deserves.

Of course next year we also hope to welcome you all to the $15^{\text {th }}$ MAF Conference being held in Bruges in Belgium in September 2017 where you will also be able to meet some of the staff working on the journal.

Finally all that remains is for us to express our thanks to all the authors, reviewers and editorial board who have supported the journal during the year by helping to maintain the high standards of research which the journal is committed to.

All good wishes for a happy and successful research New Year ahead.

David Birch, Yves Mely and Otto Wolfbeis

\footnotetext{
i Romain F Laine et al 2016 Methods Appl. Fluoresc. 4022004 http://dx.doi.org/10.1088/2050$6120 / 4 / 2 / 022004$

ii Fabienne Mérola et al 2016 Methods Appl. Fluoresc. 4012001 http://dx.doi.org/10.1088/20506120/4/1/012001

iii Miroslav D Dramićanin 2016 Methods Appl. Fluoresc. 4042001 http://dx.doi.org/10.1088/2050$\underline{6120 / 4 / 4 / 042001}$
} 
iv Matthew D Hall et al 2016 Methods Appl. Fluoresc. 4022001 http://dx.doi.org/10.1088/2050$6120 / 4 / 2 / 022001$

"Shruti Sahay et al 2016 Methods Appl. Fluoresc. 4042002 http://dx.doi.org/10.1088/2050$6120 / 4 / 4 / 042002$

Vi Marco Frasconi et al 2015 Methods Appl. Fluoresc. 3044005 http://dx.doi.org/10.1088/2050$\underline{6120 / 3 / 4 / 044005}$ 